Bull. Egypt. Soc. Physiol. Sci. 40(2), 30-43

\author{
Bull. of Egyp. Soc. Physiol. Sci. \\ (Official Journal of Egyptian Society for Physiological Sciences) \\ (pISSN: 1110-0842; eISSN: 2356-9514)
}

\title{
Nigella Sativa Seeds Afford Comparable Therapeutic Effect to that of Valsartan in Amelioration of \\ Cardiovascular Complications in Dexamethasone-induced Hypertension Model in Adult Albino Rats
}

\author{
Karima El-Sayed ${ }^{1}$, Yasser Mahmoud Awad ${ }^{2}$, Horeya Erfan ${ }^{3}$, Shimaa Mohammad Yousof ${ }^{4}$ \\ 1 Department of Medical Physiology, Faculty of Medicine, Suez Canal University, Ismailia \\ 2 Department of Agricultural Botany, Faculty of Agriculture, Suez Canal University, Ismailia \\ 3 Department of Histology, Faculty of Medicine, Suez Canal University, Ismailia \\ 4 Department of Medical Physiology, Faculty of Medicine, King Abdulaziz University, Rabigh, Saudi Arabia; \\ Department of Medical Physiology, Faculty of Medicine, Suez Canal University, Ismailia
}

Received: 28 Oct, 2019

Accepted: 24 Dec, 2019

Available online: 1 July 2020

\section{Keywords}

- Nigella Sativa

- Cardiotoxicity

- Corticosteroids

- Hypertension

- Nitric Oxide

\begin{abstract}
Aim: To identify the role of Valsartan and Nigella Sativa Seeds in amelioration of cardiovascular complications in dexamethasone-induced hypertension model in adult albino rats. Methods: Animals were randomized in into 4 groups. Group 1; a control negative group, without intervention. Group2; dexamethasone was administrated orally $(0.3 \mathrm{mg} / \mathrm{kg} /$ day $)$ for 1 month. Group 3: Nigella sativa ground seed in solution was administered orally via oral gavage $(2.5 \mathrm{mg} / \mathrm{kg} /$ day) for 5 weeks. Group 4; Valsartan was administered orally (30 mg/kg/day) for 5 weeks. Dexamethasone therapy continued in addition to the treatment in group $3 \& 4$. At day 1 baseline blood pressure measurement was done in all rats after proper conditioning for one week. Tissue homogenates were prepared for spectral assay of NO and histopathological assessment of the heart and aorta were done. Results: there was an improvement in both the systolic and diastolic blood pressures in Nigella S. and Valsartan-treated groups. NO assay showed an increment in the aorta of the Nigella-treated group only. The histopathological assessment revealed a marked improvement in the Nigella and Valsartan-treated groups with potentially better effect of Nigella S. Conclusion: Nigella S. has a better therapeutic potential in attenuating cardiovascular pathologies in rats on dexamethasone therapy.
\end{abstract}




\section{INTRODUCTION}

Hypertension is a known complication of glucocorticoids (either natural or synthetic). Corticosteroids are widely used in the treatment of a wide variety of diseases like inflammatory conditions, bronchial asthma, and allergy $(1,2)$. Management of hypertension is vital for preserving cardiovascular function (3).

Dexamethasone is a member of the synthetic corticosteroid drugs. It induces hypertension in patients on its long-term use. Dexamethasone has nearly no mineralocorticoid activity and induces hypertension via affecting the vascular resistance through nitric oxide mediation. Nitric oxide is a vasodilator that is released by the endothelium $(1,4)$.

Angiotensin receptor type I blockers (ATIR blockers) have been identified to be cardioprotective in cardiovascular diseases (5). Studies revealed that angiotensin is a proinflammatory, activates reactive oxygen species (ROS) activity, and diminishes the synthesis of endothelium-derived relaxing factor (EDRF), which is also termed as nitric oxide (eNos). Angiotensin II blockers, including Valsartan, are widely used in treating hypertension. Besides, ATIR overactivity stimulates the oxidative stress signaling and leads to activation of the inflammatory process and fibrosis (6-9).

Phytomedicine is produced from plant parts like seed, leaves, and roots for their phytochemical components, including polyphenols, tannins, steroids, and carbohydrates (10). The world health organization revealed that most of the communities in the limited income countries depend mainly on natural remedies due to their inability to afford allopathic medicines
(11). Among these natural remedies, N. Sativa seeds (also called; black cumin) exert a wide variety of beneficial pharmaceutical actions including antihypertensive, antioxidant and antiinflammatory properties due to their biologically active ingredients $(12,13)$. The identified major bioactive element in the $N$. Sativa is called "thymoquinone" (14). Nevertheless, the seeds also have many other bioactive constituents, including vitamin $\mathrm{C}$, fixed and volatile oils, carbohydrates, proteins, minerals, saponins, and alkaloids $(11,15)$.

Many studies have investigated the antiinflammatory and antihypertensive effects of valsartan or N. Sativa separately. Moreover, numerous researches on the antihypertensive role of Nigella seeds or thymoquinone as its active constituent have investigated nitric oxide deficiency-induced models (16). However, most of these studies investigated the cardioprotective properties, but no attempt has been made for the cardiotherapeutic potential of $N$. Sativa To our knowledge, this is the first study to focus on the cardiotherapeutic role of Nigella $\mathrm{S}$. in the animal model of dexamethasone-induced hypertension.

\section{Subjects \& Methods}

\section{Animals \& Experiment}

Twenty-four adult male albino rats weighting $220 \pm 20 \mathrm{gm}$. Animals were purchased from the ophthalmology research institute in Giza, Egypt. The animals were kept in the animal house with optimal husbandry conditions for one week to acclimate before the beginning of the experiment in the Physiology Department, Faculty of Medicine, Suez Canal University. Rats were fed on a standard chow diet with free access to water at controlled room temperature. 
At the beginning of the experiment, rats were assigned randomly into four groups; each of which included six rats. Group 1: a control negative group without intervention. The other three groups where kept on dexamethasone therapy via oral gavage at a concentration of $0.3 \mathrm{mg} / \mathrm{kg} /$ day (17) for one month to ensure the occurrence of cardiotoxicity. After that the rats where randomly assigned into Group 2: a control positive group in which dexamethasone was continued; Group 3: N. Sativa treated group, in which $2.5 \mathrm{mg} / \mathrm{kg} /$ day fine powder of $N$. Sativa seeds in solution was administered via oral gavage (18) and Group 4: Valsartan treated group, in which Valsartan was administered via oral gavage at a concentration of $30 \mathrm{mg} / \mathrm{kg} /$ day (19). Dexamethasone was continued in all treated groups (2, 3 and 4) for five weeks (duration of the treatment). On day one and before the introduction of any drugs, baseline blood pressure measurement was done in all rats and another measurement was done prior the introduction of the treatment to ensure the presence of hypertension as an indicator of cardiovascular pathology.

\section{Arterial blood pressure (ABP) assessment in conscious rats}

\section{Animal Preparation}

Arterial blood pressure was recorded by the tail cuff technique using a BIOPAC 150 system, after proper conditioning for one week before the study begins. The rat was located in the holder at least 10 to 15 minutes prior to $\mathrm{ABP}$ assessment. Appropriate handling of rats was considered to ensure accurate ABP measurements by avoiding stress on rats.

\section{Blood pressure measurement procedure}

The sensor was connected to the rat tail inside the restrainer of arterial blood pressure measurement. The sensor was placed between the mid-point and endpoint of the rat tail. The traces of the measured blood pressure were saved for later offline analysis of the systolic and diastolic ABP according to the recommended procedures of the BIOPAC 150 system.

\section{Histopathological assessment of heart and} blood vessels:

At the end of the experiment, all rats were euthanized with chloral hydrate. Heart and aorta were collected. The fixation of specimens was done in $10 \%$ neutral buffered formalin for 24 hours at room temperature $\left(23-28^{\circ} \mathrm{C}\right)$, and then, $5 \mu \mathrm{m}$ thick paraffin sections were prepared. The obtained sections were stained using Haematoxylin \& Eosin stain $(\mathrm{H} \& \mathrm{E})$ for the general architecture of the aorta \& heart. The collagen fibers in the heart were stained with Masson's trichrome stain while elastic fibers in the tunica media of the aorta were stained with orcein stain. Image J software was used to quantify the following: 1) the percentage of the green-colored collagen fibers in longitudinal sections of cardiac muscles, 2) The length of tunica media in Orcein stained section of the aorta, and 3) the length of tunica adventitia of the aorta section stained with Masson's Trichrome.

\section{Quantification of the severity of tissue damage (scoring):}

Regarding the cardiac tissue, the severity of changes was quantitated from none (-) to severe $(+++)$ based on the degree of inflammation, disruption of myocardial fibers and hemorrhage. The scoring system was as follows: $(-)$, no 
damage; $(+)$, minimal inflammatory cell infiltration, disruption of myocardial fibers and hemorrhage (less than 5\%); $(++)$, moderate inflammatory cell infiltration, patchy disruption of myocardial fibers and hemorrhage (5-20\%); $(+++)$, widespread inflammatory cell infiltration, disruption of myocardial fibers and hemorrhage (more than 20\%).

Concerning the aortic tissue, the severity of changes was quantitated from none (-) to severe $(+++)$ based on the surface regularity, proliferating smooth muscle fibers and thickened tunica media. The scoring system was as follows: (-), no damage; $(+)$, nearly smooth surface, proliferating smooth muscle fibers and thickened tunica media (less than 5\%); $(++)$, moderate rough surface, proliferating smooth muscle fibers and thickened tunica media (5-20\%); (+++), widespread rough surface, proliferating smooth muscle fibers and thickened tunica media (more than $20 \%$ ).

\section{Tissue homogenates:}

The heart and blood vessel tissues were homogenized according to the instruction of the kit producer. Kits were obtained from Biodiagnostic; diagnostic and research reagents, Egypt. Before dissection, perfusion of tissues with phosphatebuffered saline (PBS) solution at $\mathrm{pH} 7.4$ has been carried out. Homogenization of the tissue in 5-10 $\mathrm{ml}$ cold per gram tissue has been done. Spectrophotometric analysis of the homogenate has been carried out in a specialized laboratory.

\section{Spectral assay of Nitric Oxide (NO)}

The tissue homogenate of heart and aorta were kept frozen at $-80^{\circ} \mathrm{C}$. Standard sodium nitrite reagent was mixed with sulphanilamide and $\mathrm{N}-(1-$ naphthyl)-ethylenediamine (NEDA) according to the protocol recommended by the producer (Biodiagnostic; diagnostic and research reagents, Egypt). Colorimetric determination of nitrite in the tissue homogenate was done against standard blank of 520-550 nm. The nitrite concentration in samples was then calculated $(\mu \mathrm{mol} / \mathrm{L})$.

\section{Data analysis:}

Data were statistically analyzed via IBM SPSS software version 23. Data were expressed as mean \pm SD and ANOVA post hoc LSD and t-test were used to compare means.

\section{Ethical considerations:}

All experimental procedures on animals used for the current study followed the recommendations of the Faculty of Medicine's Ethical Committee at the Suez Canal University, Ismailia, Egypt.

\section{Results:}

\section{Arterial blood pressure:}

The ABP of the control group was (mean \pm SD: $119 \pm 11.1 / 70 \pm 4.9 \mathrm{mmHg}$ ). The results revealed statistically significant diminishment in the systolic and diastolic blood pressures in the treated groups. The N. Sativa group revealed a significant decrement in the systolic and diastolic ABP (mean \pm SD $139 \pm 17.4 / 77 \pm 4.4$ ) compared to the dexamethasone group $(180 \pm 0.01 / 98 \pm 2.9) ; P$ value $\leq 0.001$ and $\leq 0.008$; respectively. Valsartan group showed a significant decrement in the systolic \& diastolic ABP compared to the dexamethasone group (mean \pm SD: $144 \pm 5.8 / 80 \pm 7.7$, $180 \pm 0.01 / 98 \pm 2.9, P$-value $\leq 0.04$ and $\leq 0.001$; respectively). There were no significant differences in systolic and diastolic blood pressures $(P$-value $\geq 0.5)$ among the $N$. Sativa and 
Valsartan groups, indicating almost comparable reduction in the blood pressure by both treatments (Fig.1).

\section{Nitric oxide concentration in the aorta and heart tissue homogenates}

N. Sativa has significantly decreased the cardiac NO concentration compared to the control group $($ mean \pm SD: $0.2 \pm 0.17$ and $1.33 \pm 0.30$, respectively, $P$-value $\leq 0.003)$. Meanwhile, it significantly increased the NO level in the aorta compared to the control group (mean \pm SD: $2.08 \pm$ 0.88 and $0.96 \pm 0.045 \mathrm{mmol} / \mathrm{L}$, respectively; $P$ value $\leq 0.04)$. There were no statistical differences in NO level among the other groups (Fig. 2).

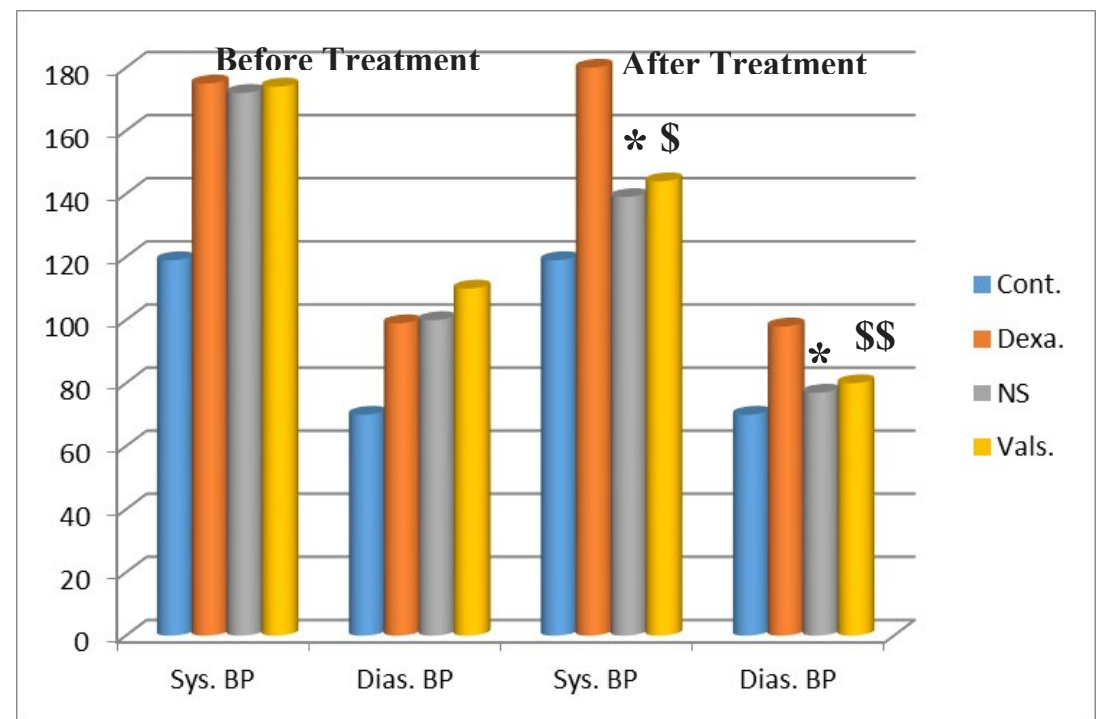

Figure 1: Changes in the Systolic and Diastolic Blood Pressure (mmHG) before and after Treatment in Each Group. The $N$. Sativa and Valsartan groups are compared to dexamethasone group after treatment.

***: P-value $\leq 0.001$ and $\leq 0.008$; respectively.

$\$$, $\$$ : $P$-value $\leq 0.04$ and $\leq 0.001$; respectively

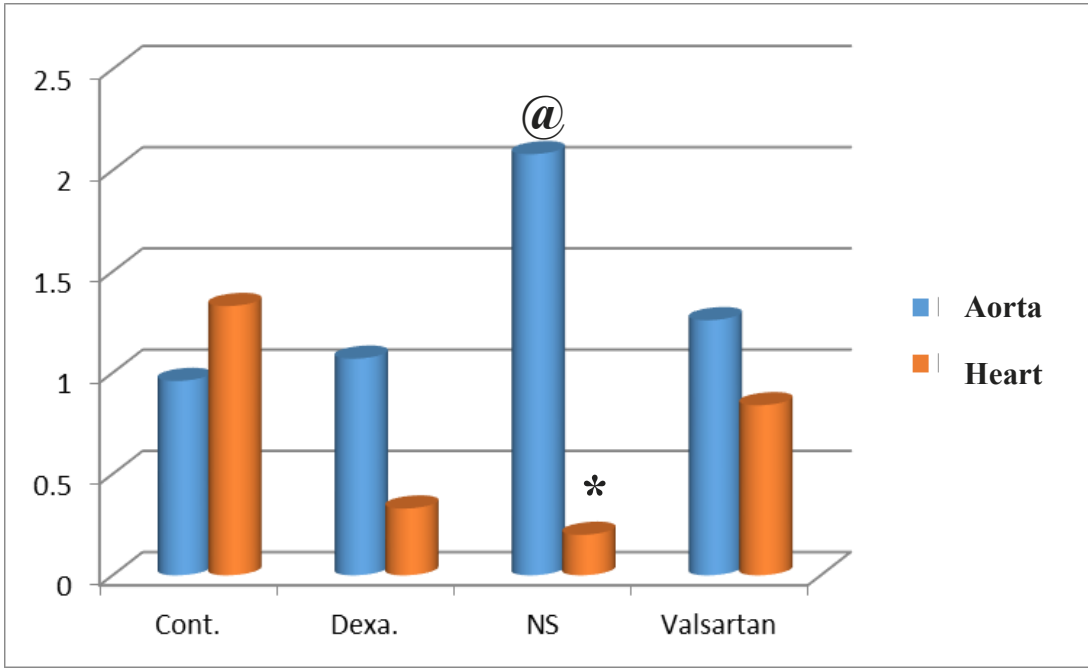

Figure 2: Nitric oxide level $(\mathrm{Mmol} / \mathrm{L})$ in the Aorta and Heart Tissue Homogenate in Each Group. ${ }^{*} P$-value $\left.\leq 0.003\right)$ and (a) P-value $\leq 0.04)$. 
Histopathological assessment of the cardiac muscle

Figures 3-6 showed histopathological examination of the cardiac muscles from different groups. Fig 3 showed normal myocardial morphology in negative control group. H\&E stained sections of the heart of the dexamethasone group showed marked histopathological as shown in Fig.4a. Nigella-treated group displayed regain of the normal histological appearance as shown in
Fig.5a. Valsartan-treated group revealed nearly normal architecture as displayed in Fig.6a.

Masson's trichrome stained sections of the control group showed normal histological structure; Fig.3b. Whereas, the hypertensive dexamethasone group showed marked increase of collagen fibers connective tissue (greenish discoloration) in between cardiac muscles; Fig.4b. Nigella- \& Valsartan-treated groups showed regression of these pathologic features Fig. $5 \mathrm{~b} \&$ Fig.6b.

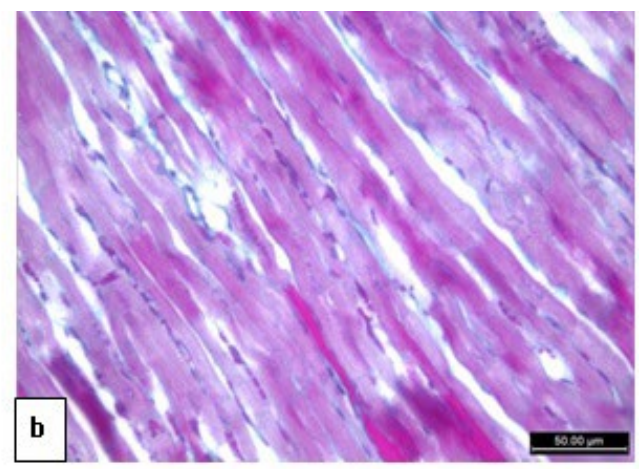

Fig. 3: A longitudinal section in the heart of a control negative group (group 1).
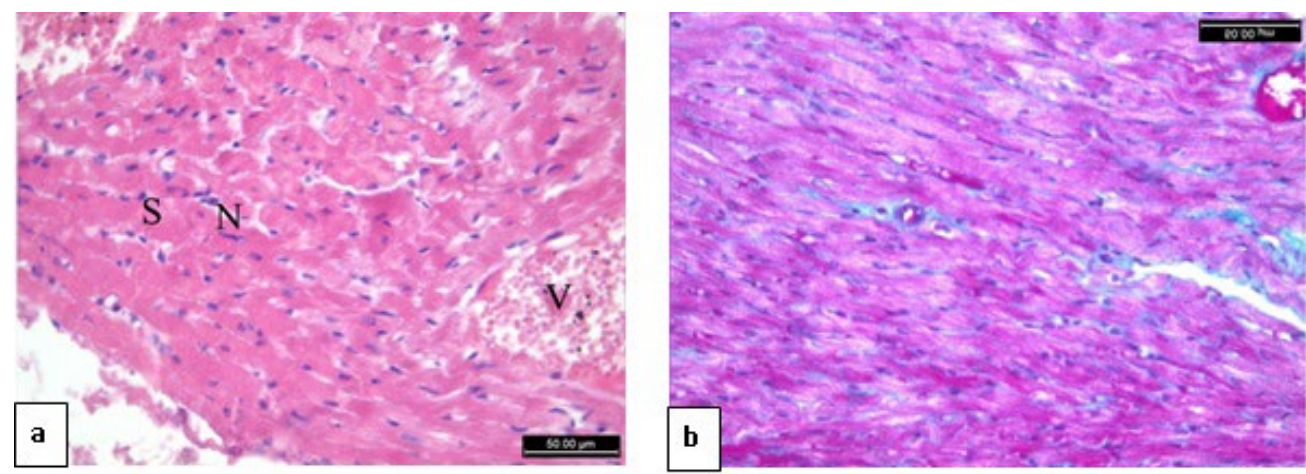

Fig 4: A longitudinal section in the cardiac muscle of the hypertensive group (group 2).
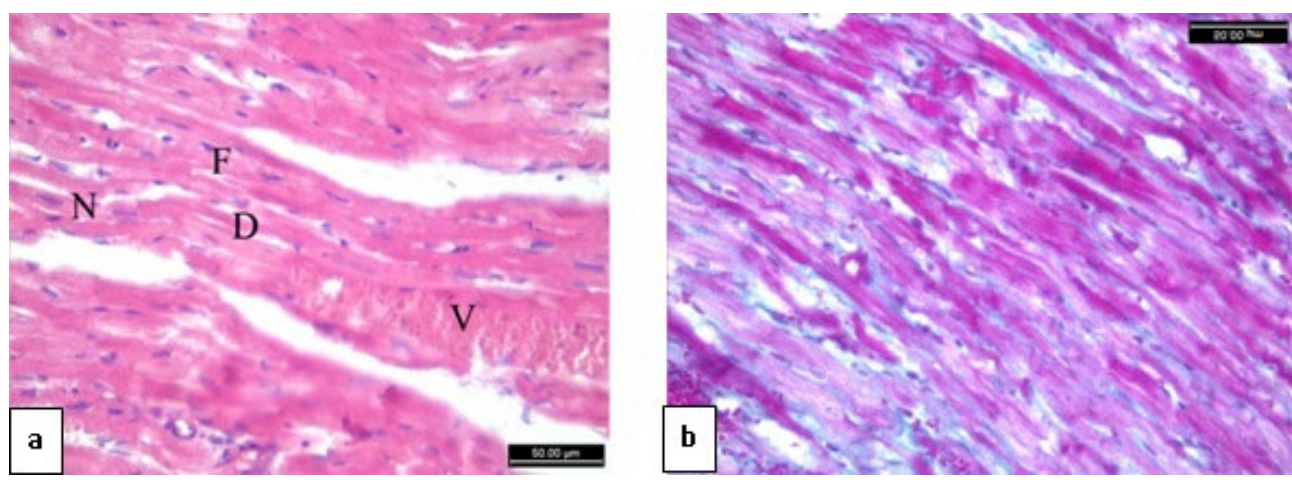

Fig 5. A longitudinal section in the cardiac muscle of $N$. Sativa treated group (group 3). 

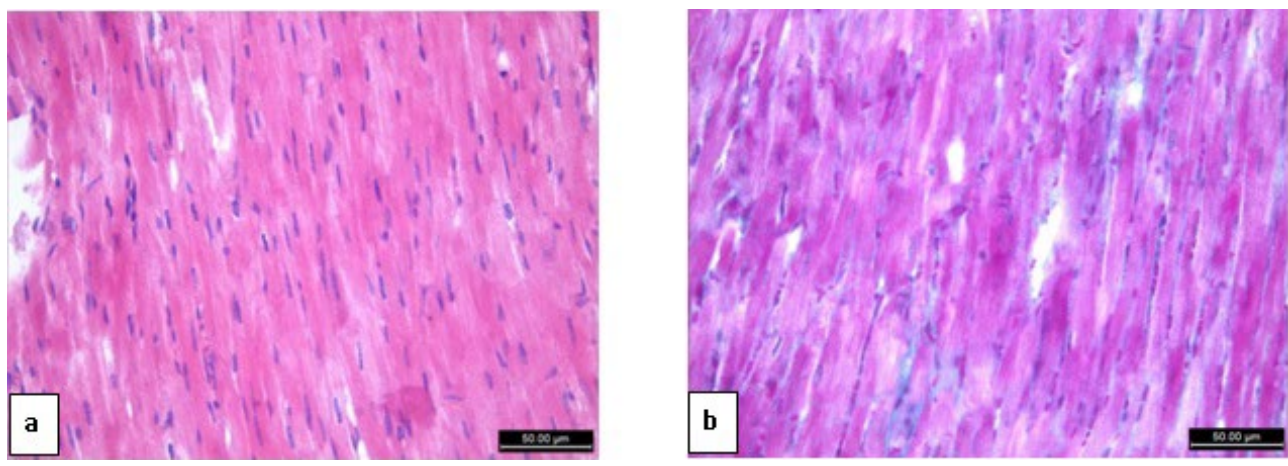

Fig. 6: A longitudinal section in the cardiac muscle from Valsartan treated group (group 4).

Histopathological assessment of the blood vessel (aorta):

Qualitative assessment of the histopathological changes using $\mathrm{H} \& \mathrm{E}$ stain in the aorta revealed normal appearance of tunica intima media and adventitia; Fig. 7a. The hypertensive group showed obvious histopathological abnormalities in the form of relative irregularities of the tunica intima with a fairly rough surface, proliferating smooth muscle fibers of the thickened tunica media and fibrosed tunica adventitia; Fig. 8a. The aorta of Nigella- and Valsartan-treated groups revealed improvement of the pathological abnormalities occurred in response to dexamethasone; Fig. 9a. \& Fig. 10a.

Orcein stained sections of control group showed a thick parallel regularly arranged elastic laminae appeared as regular, continuous wavy and dark brown line; Fig. 7b. The hypertensive group revealed a relatively thin elastic laminae that appeared fragmented and formed a network of thin fibrils in some areas; Fig. 8b. Nigella-treated group histological structure appeared nearly normal with restoration of the regular continuous wavy and dark brown line; Fig. 9b. The aorta of Valsartantreated group revealed relatively thin elastic laminae that appeared as a network of thin fibrils in some areas; Fig. 10b.

Masson's trichrome stained sections of the control group showed a greenish coloration of collagen fibers in the media and the tunica adventitia; Fig.7c. Hypertensive group showed marked increase the greenish collagenous fibers of the tunica adventitia; Fig.8c. Nigella \& Valsartantreated groups showed an increase in the greenish collagenous fibers of the tunica adventitia but less than the hypertensive group; Fig.9c \& Fig.10c.

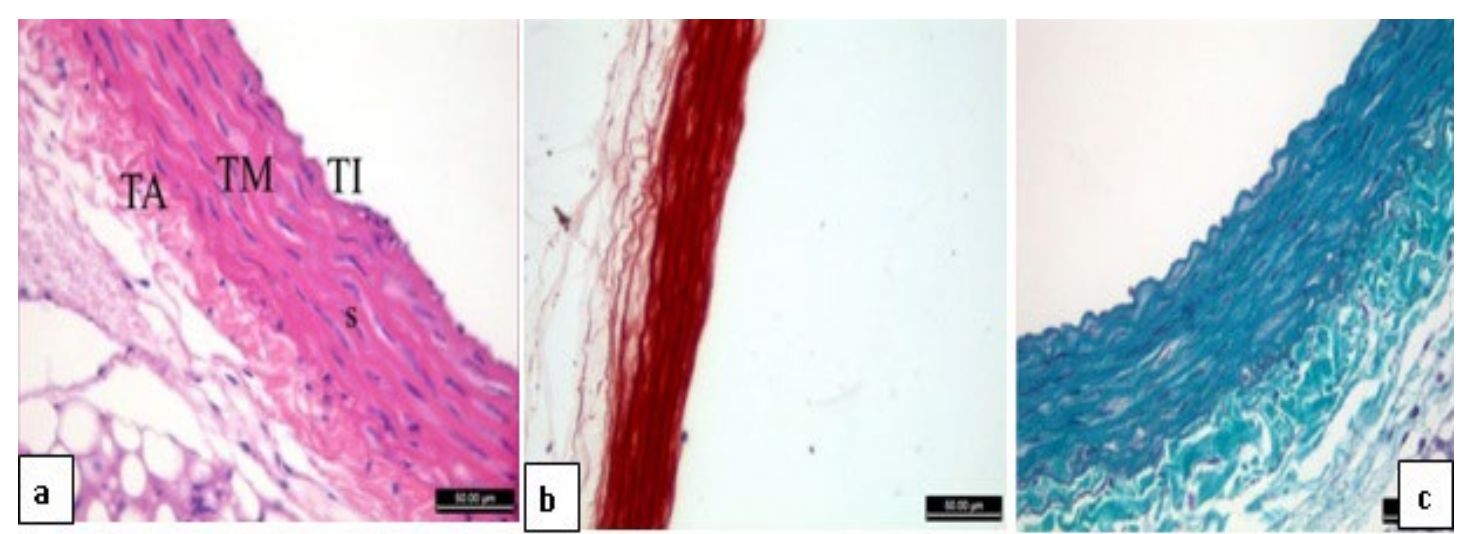

Fig.7: The aorta of the negative control group (group 1). 


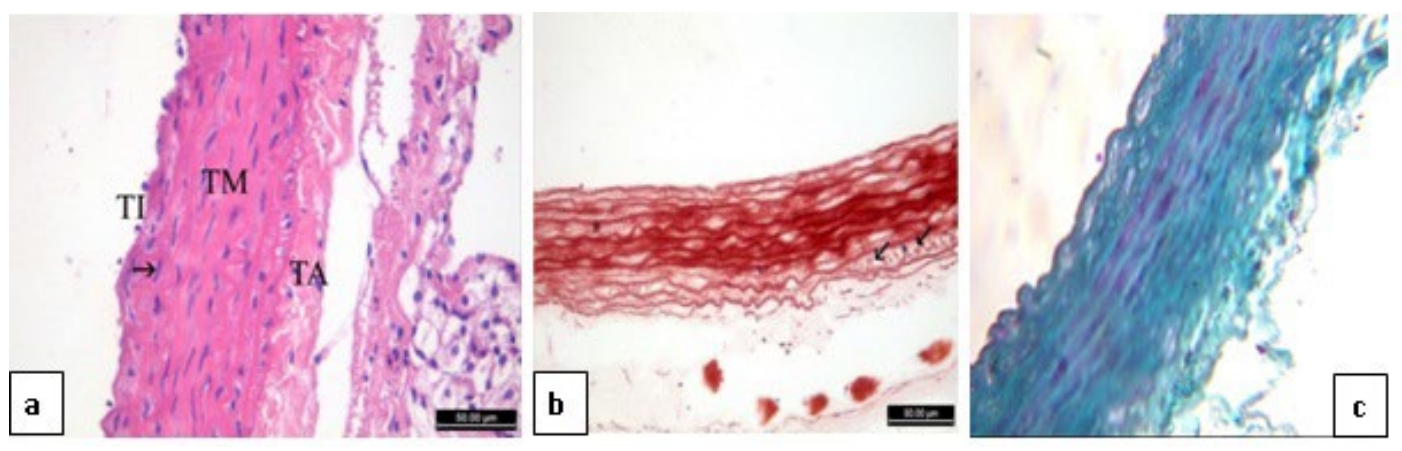

Fig.8: The aorta of the dexamethasone group (group 2).

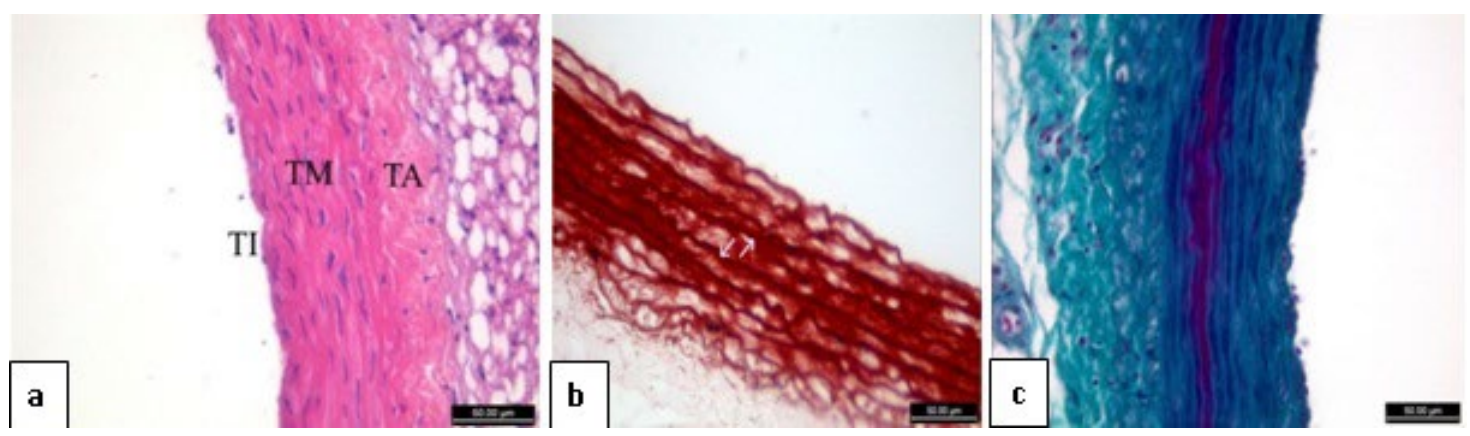

Fig.9: The aorta of N. Sativa treated group (group 3).

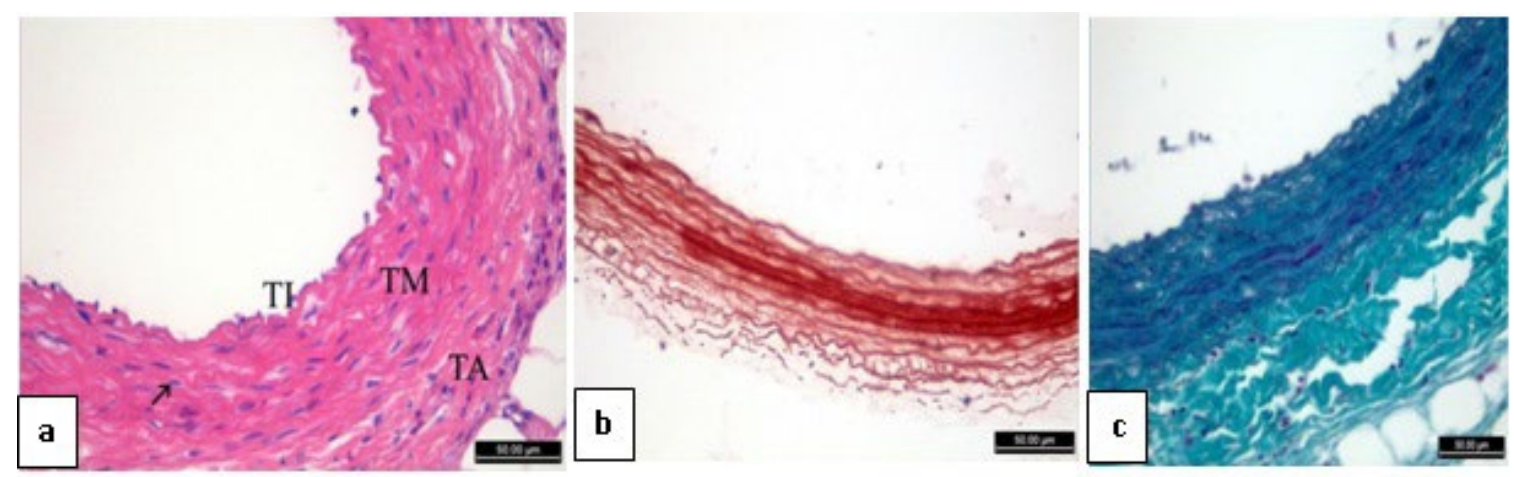

Fig.10: The aorta of Valsartan treated group (group 4).

\section{Results of quantification of the severity of tissue damage:}

On examining the cardiac tissue, the dexamethasone group revealed a variable degree of pathological damage in the form of inflammation, disruption of myocardial damage and hemorrhage ranging between moderate to widespread damage. The pathological features regressed nearly to normal (mild damage) in the $N$. Sativa group. On the other hand the Valsartan group showed lesser regression of the pathological features (mild to moderate); Table 4.
Examination of the aortic tissue revealed pathological changes in the form of roughened surface, proliferation of the smooth muscle fibers and thickening of tunica media ranging between (moderate to widespread) in the dexamethasone group. These changes were regressed in both the $N$. Sativa and Valsartan groups regarding the rough surface (normal to mild). While the proliferating muscle and the thickening of tunica media were regressed more in the $N$. Sativa (normal to mild) group compared to Valsartan (mild to moderate); Table 5. 
Table (1): The length of tunica media of aorta in the different experiment groups:

\begin{tabular}{|l|l|}
\hline Group & Length (Mean \pm S.D.) \\
\hline Control & $153.87 \pm 9.19$ \\
\hline Dexamethasone & $282.18 \pm 28.18^{*}$ \\
\hline N. Sativa & $203.24 \pm 12.6^{*}$ \\
\hline Valsartan & $219.57 \pm 6.016^{*}$ \\
\hline \multicolumn{2}{|l|}{ *Statistically significance compared to control }
\end{tabular}

Table (2): The length of tunica adventitia of aorta in the different experiment groups:

\begin{tabular}{|l|l|}
\hline Group & Length (Mean \pm S.D.) \\
\hline Control & $132.02 \pm 10.29$ \\
\hline Dexamethasone & $443.9 \pm 74.99^{*}$ \\
\hline N. Sativa & $236.94 \pm 68.06^{*} \#$ \\
\hline Valsartan & $242.33 \pm 30.5^{*} \#$ \\
\hline
\end{tabular}

\#* Statistically significance compared to control, Statistically significance compared to group II

Table (3): The mean color area percentage of green collagen fibers in between cardiac muscles in the different experiment groups:

\begin{tabular}{|l|l|}
\hline Group & $\begin{array}{l}\text { Mean color area percentage of collagen } \\
\text { (Mean } \pm \text { S.D. })\end{array}$ \\
\hline Control & $16.338 \pm 0.433$ \\
\hline Dexamethasone & $21.85 \pm 0.67 *$ \\
\hline N. Sativa & $18.29 \pm 0.54 *$ \\
\hline Valsartan & $19.33 \pm 0.16 *$ \\
\hline
\end{tabular}

Table (4): Scoring of the morphological features as assessed by histopathological examination of heart

\begin{tabular}{|l|c|c|c|}
\hline Group & Inflammation & $\begin{array}{c}\text { Disruption of } \\
\text { myocardial fibers }\end{array}$ & Hemorrhage \\
\hline Control & $(-)$ & $(-)$ & $(-)$ \\
\hline Dexamethasone & $(++)$ to $(+++)$ & $(++)$ to $(+++)$ & $(++)$ to $(+++)$ \\
\hline N. Sativa & $(-)$ to $(+)$ & $(-)$ to $(+)$ & $(-)$ to $(+)$ \\
\hline Valsartan & $(+)$ to $(++)$ & $(+)$ to $(++)$ & $(+)$ to $(++)$ \\
\hline
\end{tabular}

$(-)$, no damage; $(+)$, minimal (less than 5\%); (++), moderate (5-20\%); (+++), widespread (more than 20\%).

Table (5): Scoring of the morphological features as assessed by histopathological examination of the aorta

\begin{tabular}{|l|c|c|c|}
\hline Group & Rough surface & $\begin{array}{c}\text { Proliferating smooth } \\
\text { muscle fibers }\end{array}$ & $\begin{array}{c}\text { Thickened tunica } \\
\text { media }\end{array}$ \\
\hline Control & $(-)$ & $(-)$ & $(-)$ \\
\hline Dexamethasone & $(++)$ to $(+++)$ & $(++)$ to $(+++)$ & $(++)$ to $(+++)$ \\
\hline N. Sativa & $(-)$ to $(+)$ & $(-)$ to $(+)$ & $(-)$ to $(+)$ \\
\hline Valsartan & $(-)$ to $(+)$ & $(+)$ to $(++)$ & $(+)$ to $(++)$ \\
\hline
\end{tabular}

$(-)$, no damage; $(+)$, minimal (less than 5\%); (++), moderate $(5-20 \%) ;(+++)$, widespread (more than $20 \%)$.

\section{Discussion}

Corticosteroid therapy is usually used in chronic and potentially irritating conditions for the patients (20). Combating hypertension-induced pathologies in patients on prolonged corticosteroid therapy is a matter of concern. Dexamethasone mediates hypertension and cardiovascular changes by different mechanisms such as its adverse effects on vascular endothelium and smooth muscle cells. It increases the proliferation of the vascular smooth muscle cells, and leads to endothelial cell dysfunction and remodeling. Moreover, it leads to oxidative stress damage, superoxide anion production, and deterioration of arterial wall elastic material $(4,21)$. In the present study, the ABP measurements revealed a comparable diminishment in both Nigella S. and Valsartan groups. Our results are in accord with a previous 
study in which Nigella S. oil was introduced concomitantly with L-NAME (18).

In the present study, the ABP measurements revealed a comparable diminishment in both $N$. Sativa and Valsartan groups. Our results are in accord with a previous study in which $N$. Sativa oil was introduced concomitantly with L-NAME (18).

In the current study, the aortic NO was significantly increased in the Nigella-treated group and an insignificantly increased in the dexamethasone and Valsartan-treated groups. Interestingly, the cardiac muscle NO, on the other hand, showed decreased levels in the N. Sativa group compared to the control group. The dexamethasone and Valsartan-treated groups showed insignificant decrease in the NO level. Yet, the blood pressure was decreased in the $N$. Sativa and Valsartan groups. These findings collectively refer to other mechanistic pathways that could be involved in the blood pressure lowering effect of $N$. Sativa \& Valsartan in dexamethasone-induced hypertension model, rather than NO involvement per se.

NO has an evident role in controlling cardiac functions such as contractility and heart rate. $\mathrm{NO}$ also restrain the ischemic remodeling. At the basal conditions, cardiac and vascular NOS is mainly involved, whilst the inducible forms are released in response to septic shock. The mechanism of controlling the cardiac contractility occurs via affecting cGMP. When NO is diminished, cGMP decreases, leading to inhibition of Phosphodiastrase III. This in turn leads to prevention of the hydrolysis of cAMP and activation of protein kinase $\mathrm{A}$, which leads to the opening of sacrolemmal voltage gated $\mathrm{Ca}_{+2}$ channels and sarcoplasmic ryanodin receptor $\mathrm{Ca}_{+2}$ channels. Therefore, increase myocardial contractility. NOS inhibition on the other hand, leads to decreased heart rate. So, collectively and under basal conditions, decreased NO leads to increased contractility and decreased heart rate. It is to be noted that the direct effect of NOS on the heart rate could be modulated upon stimulation of baroreceptors by elevated blood pressure (22). The major determinant of the cardiac output is the stroke volume (23). Therefore, we suggest that decreased blood pressure in the $N$. Sativa group could be partly attributed to the effects of lowered NO level in the cardiac muscle (decreased heart rate and increased contractility) accompanied by the decrease in peripheral resistance that occur in response to the increased vascular (aortic) NO level. This suggestion is supported by what Jarrin et al. 2015 been documented. They reported that $N$. Sativa can improve endothelial function through inhibition of oxidative stress and normalization of the renin-angiotensin system activity (18).

Valsartan acts as an AT1R antagonist, reduces endothelial cellular hypertrophy and decreases the activation of oxidative stress in the vascular smooth muscle cells $(24,25)$. The antiinflammatory effect of Valsartan is known to be mediated via blocking ATIR, and hence, affect the ROS signaling through preventing the inactivation of eNOS, stimulating NO release and improving endothelial dysfunction by modulation of oxidative stress (6). Our results, although being not statistically significant, are similar to those of Mason et al. 2014, who found that Valsartan is a highly effective experimental treatment of inflammation and stimulates NO release, which decreases reactive oxygen 
species production, oxidative stress and inhibits endothelial cell remodeling and damage (24).

Among the current study important observations, dexamethasone-induced hypertension caused the proliferation of the smooth muscle fibers and elastic lamina of the tunica media. Vascular smooth muscle cell proliferation is thought to contribute to the pathology of hypertension as a compensatory mechanism. Our study revealed that dexamethasone induced arteriosclerotic changes in the form of thickening of tunica media and tunica adventitia, an issue that may lead to cardiovascular abnormalities.

In the current work, it has been observed that $N$. Sativa seeds treatment significantly reversed most of the pathological features that have been occurring in the induced model better than Valsartan did. This finding reflects the cardio-therapeutic rather than the cardio-protective properties of N. Sativa On the other side, Valsartan treatment shared the cardio-therapeutic properties with $N$. Sativa However, the histopathological findings shed light into a better effect of Nigella.

Therefore, we can conclude that the decreased blood pressure in the Nigella group in our work could be attributed physiologically to the role of cardiac NO in modulating the interaction between the cardiac contractility and heart rate from one side and the decrease in peripheral resistance encountered by the significant increase in the aortic nitric oxide from the other side. Additionally, the regression in the cardiac and aortic tissue pathologic features occurred in response to dexamethasone in the N. Sativa group lead to normalization of the cardiovascular function and ensures its therapeutic properties in the used model.

A limitation of our study is that a group of $N$. Sativa per se was not included in the study. Moreover, we did not assess the angiotensin receptor activity, which could provide a mechanistic clue for the antihypertensive effect in the investigated model.

Collectively, the results, point to the potential therapeutic efficacy of $N$. Sativa seeds in alleviating the cardio-toxic effects of dexamethasone in the same, or probably a better, manner as Valsartan do. Yet, the mechanistic process involved in both treatments does not depend mainly on NO level, but could be attributed to other mechanisms that lead to the reversal of the cardiovascular structural abnormalities that occur in response to dexamethasone therapy. Thereby, N. Sativa could be encouraged as an effective, edible, and inexpensive plant-based therapy in patients on long-term corticosteroid therapy to combat for its cardiotoxicity.

\section{Conflict of interest:}

The authors declare no conflict of interest.

\section{Funding:}

This research is completely funded by the authors.

\section{Author contribution:}

KEl-S: generating the idea of the research, methodology formulation and follow up of laboratory experiments, editing the paper \& discussing the results. $\boldsymbol{Y A}$ : discussing the study protocol and the method of introduction of Nigella sativa, follow up of laboratory experiments and scarification of rats, and editing the paper. $\boldsymbol{H E}$ : performing \& editing the methodology of histopathologic assessment, performing statistical 
analysis, discussing as well as editing of their results. ShY: generating the idea of the research, methodology formulation and follow up of laboratory experiments, editing the paper, statistical analysis and discussing the results, and building of the infographic summary.

Acknowledgment: we provide our gratitude to Dr. Ayman Salah Salem, specialist of clinical pathology, Ministry of Health, Egypt; for his cooperation on analyzing tissue homogenate specimens for $\mathrm{NO}_{2}$ assay. Thanks in advance for Mr. Mohammad Abdel-Salam, the laboratory technician, for his great contribution in caring with the study animals.

\section{References:}

1. Ong SLH, Whitworth YZ and JA. Mechanisms of Dexamethasone-Induced Hypertension [Internet]. Current Hypertension Reviews. 2009 [cited 2019 Jul 29]. Available from: http://www.eurekaselect.com/68556/article

2. Goodwin JE, Geller DS. Glucocorticoidinduced hypertension. Pediatr Nephrol Berl Ger. 2012 Jul;27(7):1059-66.

3. Tocci G, Castello L, Volpe M. A Review of Angiotensin Receptor Blocker-based Therapies at all Levels of Cardiovascular Risk. J - Rev Angiotensin Recept Blocker-Based Ther Levels Cardiovasc Risk [Internet]. 2011 Jul 26 [cited 2019 Oct 19]; Available from: https://www.ecrjournal.com/articles/reviewangiotensin-receptor-blocker-therapies

4. Baum M, Moe OW. GlucocorticoidMediated Hypertension: Does the Vascular Smooth Muscle Hold All the Answers? J Am Soc Nephrol [Internet]. 2008 Jul 1 [cited 2019 Jul 29];19(7):1251-3. Available from: https://jasn.asnjournals.org/content/19/7/1251
5. Stojiljkovic L, Behnia R. Role of renin angiotensin system inhibitors in cardiovascular and renal protection: a lesson from clinical trials. Curr Pharm Des. 2007;13(13):1335-45.

6. Cole BK, Keller SR, Wu R, Carter JD, Nadler JL, Nunemaker CS. VALSATARN PROTECTS PANCREATIC ISLETS AND ADIPOSE TISSUE FROM THE INFLAMMATORY AND METABOLIC CONSEQUENCES OF A HIGH-FAT DIET IN MICE. Hypertension [Internet]. 2010 Mar [cited 2019 Jul 29];55(3):715-21. Available from: https://www.ncbi.nlm.nih.gov/pmc/articles/PMC2 $836256 /$

7. Leong X-F, Rais Mustafa M, Jaarin K. Nigella sativa and Its Protective Role in Oxidative Stress and Hypertension [Internet]. EvidenceBased Complementary and Alternative Medicine. 2013 [cited 2019 Sep 19]. Available from: https://www.hindawi.com/journals/ecam/2013/120 $732 /$

8. Ramadan R, Dhawan SS, Binongo JNG, Alkhoder A, Jones DP, Oshinski JN, et al. Effect of Angiotensin II Type I Receptor Blockade with Valsartan on Carotid Artery Atherosclerosis: A Double Blind Randomized Clinical Trial Comparing Valsartan and Placebo (EFFERVESCENT). Am Heart J [Internet]. 2016 Apr [cited 2019 Jul 29];174:68-79. Available from:

https://www.ncbi.nlm.nih.gov/pmc/articles/PMC4 800491/

9. Cheng Y-Q, Tan B-Y, Yu X-H, Dong W-Z, Su D-F, Zhu D-Q, et al. Synergism of amlodipine and candesartan on blood pressure reduction and organ protection in hypertensive rats. Clin Exp Pharmacol Physiol [Internet]. 2018 
[cited 2019 Sep 26];45(6):514-24. Available from: https://onlinelibrary.wiley.com/doi/abs/10.1111/14 40-1681.12901

10. Rashid S, Zafar M, Ahmad M, Lone FA, Shaheen S, Sultana S, et al. Microscopic investigations and pharmacognostic techniques used for the standardization of herbal drug Nigella sativa L. Microsc Res Tech [Internet]. 2018 [cited 2019 Sep 24];81(12):1443-50. Available from: https://onlinelibrary.wiley.com/doi/abs/10.1002/je mt.23110

11. Yimer EM, Tuem KB, Karim A, UrRehman N, Anwar F. Nigella sativa L. (Black Cumin): A Promising Natural Remedy for Wide Range of Illnesses [Internet]. Evidence-Based Complementary and Alternative Medicine. 2019 [cited 2019 Sep 19]. Available from: https://www.hindawi.com/journals/ecam/2019/152 $8635 /$

\section{Niazmand S, Fereidouni E,} Mahmoudabady M, Mousavi SM. EndotheliumIndependent Vasorelaxant Effects of Hydroalcoholic Extract from Nigella sativa Seed in Rat Aorta: The Roles of Ca2 [Internet]. BioMed Research International. 2014 [cited 2019 Sep 19]. Available from: https://www.hindawi.com/journals/bmri/2014/247 054/

13. Ikhsan M, Hiedayati N, Maeyama K, Nurwidya F. Nigella sativa as an antiinflammatory agent in asthma. BMC Res Notes [Internet]. 2018 Oct 19 [cited 2019 Jul 30];11(1):744. Available from: https://doi.org/10.1186/s13104-018-3858-8

14. Bouhlel A, Bejaoui M, Mosbah IB, Abdallah NH, Ribault C, Viel $R$, et al. Thymoquinone protects rat liver after partial hepatectomy under ischaemia/reperfusion through oxidative stress and endoplasmic reticulum stress prevention. Clin Exp Pharmacol Physiol [Internet]. 2018 [cited 2019 Sep 24];45(9):943-51. Available from:

https://onlinelibrary.wiley.com/doi/abs/10.1111/14 40-1681.12961

\section{Bordoni L, Fedeli D, Nasuti C, Maggi F,} Papa F, Wabitsch M, et al. Antioxidant and AntiInflammatory Properties of Nigella sativa Oil in Human Pre-Adipocytes. Antioxidants [Internet]. 2019 Feb 25 [cited 2019 Jul 30];8(2). Available from:

https://www.ncbi.nlm.nih.gov/pmc/articles/PMC6 406245/

16. Khattab M, Nagi M. Thymoquinone Supplementation attenuates Hypertension and Renal Damage in Nitric Oxide deficient Hypertensive Rats. Phytother Res PTR. 2007 May $1 ; 21: 410-4$.

17. Soto-Piña AE, Franklin C, Rani CSS, Gottlieb H, Hinojosa-Laborde C, Strong R. A Novel Model of Dexamethasone-Induced Hypertension: Use in Investigating the Role of Tyrosine Hydroxylase. J Pharmacol Exp Ther. 2016;358(3):528-36.

18. Jaarin K, Foong WD, Yeoh MH, Kamarul ZYN, Qodriyah HMS, Azman A, et al. Mechanisms of the antihypertensive effects of Nigella sativa oil in L-NAME-induced hypertensive rats. Clinics [Internet]. 2015 Nov [cited 2019 Sep 22];70(11):751-7. Available from: http://www.scielo.br/scielo.php?script=sci_abstrac t\&pid=S1807-

59322015001100751\&lng=en\&nrm=iso\&tlng=en

19. Han Y, Su C, Ou B. [The effect and mechanism of felodipine and valsartan on a novel 
salt-sensitive hypertensive rat induced by sensory denervation]. Zhonghua Xin Xue Guan Bing Za Zhi. 2005 Mar;33(3):255-9.

20. HATTORI T, MURASE T, IWASE E, TAKAHASHI K, OHTAKE M, TSUBOI K, et al. GLUCOCORTICOID-INDUCED HYPERTENSION AND CARDIAC INJURY: EFFECTS OF MINERALOCORTICOID AND GLUCOCORTICOID

RECEPTOR ANTAGONISM. Nagoya J Med Sci [Internet]. 2013 Feb [cited 2019 Oct 19];75(1-2):81-92. Available from: https://www.ncbi.nlm.nih.gov/pmc/articles/PMC4 345706/

21. Iuchi Takahiko, Akaike Masashi, Mitsui Takao, Ohshima Yasushi, Shintani Yasumi, Azuma Hiroyuki, et al. Glucocorticoid Excess Induces Superoxide Production in Vascular Endothelial Cells and Elicits Vascular Endothelial Dysfunction. Circ Res [Internet]. 2003 Jan 10 [cited 2019 Oct 19];92(1):81-7. Available from: https://www.ahajournals.org/doi/10.1161/01.RES. 0000050588.35034.3C

22. Rastaldo R, Pagliaro $\mathbf{P}$, Cappello $\mathbf{S}$, Penna C, Mancardi D, Westerhof N, et al. Nitric oxide and cardiac function. Life Sci. 2007 Aug 16;81(10):779-93.

23. King J, Lowery DR. Physiology, Cardiac Output. In: StatPearls [Internet]. Treasure Island (FL): StatPearls Publishing; 2019 [cited 2019 Dec $12]$. Available from: http://www.ncbi.nlm.nih.gov/books/NBK470455/ 24. Mason R. Preston, Jacob Robert F, Malinski Tadeusz. Abstract 648: Nebivolol and Valsartan Increase Nitric Oxide Release from Human Endothelial Cells in a Synergistic Fashion. Hypertension [Internet]. 2014 Sep 1 [cited 2019
Oct 22];64(suppl_1):A648-A648. Available from: https://www.ahajournals.org/doi/10.1161/hyp.64.s uppl_1.648

25. Wen H, Gwathmey JK, Xie L-H. Oxidative stress-mediated effects of angiotensin II in the cardiovascular system. World J Hypertens [Internet]. 2012 Aug 23 [cited 2019 Oct 22];2(4):34-44. Available from: https://www.ncbi.nlm.nih.gov/pmc/articles/PMC3 936474/ 